\title{
COPING STRATEGY AS A WAY TO PREVENT EMOTIONAL BURNOUT IN PRIMARY CARE DOCTORS: A RANDOMIZED CONTROLLED TRIAL
}

\section{Sergey LEE ${ }^{1 \bowtie}$, Zarina ROZYBAKIEVA ${ }^{1}$, Marat ASIMOV ${ }^{1}$, Fatima BAGIYAROVA ${ }^{1}$, Aygul TAZHIYEVA ${ }^{1}$, Neilya USSEBAYEVA ${ }^{2}$, Timur SALIEV ${ }^{1}$, Shynar TANABAYEVA ${ }^{1}$, IIdar FAKHRADIYEV ${ }^{1}$}

${ }^{1}$ S.D. Asfendiyarov Kazakh National Medical University, Republic of Kazakhstan

${ }^{2}$ Kazakh Medical University of Continuing Education, Almaty, Kazakhstan

Received 11 May 2020, Accepted 15 July 2020

https://doi.org/10.31688/ABMU.2020.55.3.04

\begin{abstract}
Introduction. Burnout is one of the major unresolved problems of healthcare professionals. Considering the recent situation with COVID-19 and associated psychological stress, this issue becomes high-critical over the world.

Objective. The study aimed at validating the effectiveness of Asimov's coping strategy among a group of primary care physicians in reducing emotional burnout.

Material and methods. The study was conducted in Almaty (Kazakhstan). The volunteers $(\mathrm{N}=243)$ were randomly divided into intervention group (IG) and control group (CG). In the IG, short-term psychotherapy based on the coping strategy (Asimov method) was implemented. Methods of measurement of emotional burnout included the use of emotional burnout ('Maslach') and Lazarus questionnaires. In addition, factors related to demography, work, and lifestyle were assessed as well.
\end{abstract}

Results. The assessment of the emotional burnout showed a high level of emotional burnout in both groups $(p>0.05)$. After 6 months, emotional

\section{RéSUMÉ}

La stratégie d'adaptation en tant que moyen de prévenir l'épuisement émotionnel chez les médecins de soins primaires : un essai contrôlé randomisé

Introduction. L'épuisement professionnel est l'un des principaux problèmes non résolus des professionnels de la santé. Compte tenu de la situation récente de l'infection au COVID-19 et du stress psychologique associé, ce problème devient extrêmement critique dans le monde.

Objectif. L'étude visait à valider l'efficacité de la stratégie d'adaptation d'Asimov auprès d'un groupe de médecins de soins primaires pour réduire l'épuisement émotionnel.

Materiel et méthodes. L'étude a été menée à Almaty (Kazakhstan). Les volontaires $(\mathrm{N}=243)$ ont été répartis au hasard en groupes d'intervention (IG) et témoins (CG). Dans le groupe IG, une psychothérapie de courte durée basée sur la stratégie d'adaptation (méthode Asimov) a été mise en place. Les méthodes de mesure de l'épuisement émotionnel comprenaient 
exhaustion (EE) ( $\mathrm{p}=0.019)$ and depersonalization (DP) $(p=0.028)$ indicators in the IG group were reduced, in contrast to the CG group, except for the lack of personal achievement (PA) $(\mathrm{p}=0.067)$. However, after 12 months, indicators of EE and DP were decreased, at the same time the PA indicator was elevated in the IG group ( $\mathrm{p}<0.05)$. The data of the study based on the Lazarus questionnaire (12 months) showed the effectiveness of this method $(\mathrm{p}<0.05)$.

Conclusions. The use of Asimov's coping strategy showed a positive effect on the emotional status of primary care physicians. Such a strategy possesses the potential for the management of the psychological stability of doctors who underwent emotional burnout.

Keywords: emotional burnout, coping strategy, primary care physician.

\author{
Abbreviations \\ $\mathrm{IG}=$ intervention group \\ $\mathrm{CG}=$ control group \\ $\mathrm{EE}=$ emotional exhaustion \\ $\mathrm{DP}=$ depersonalization \\ $\mathrm{PA}=$ absence of personal achievements
}

\section{INTRODUCTION}

Burnout syndrome among healthcare professionals is a complex of psychological symptoms linked to professional activity. The burnout has been associated with emotional exhaustion, depersonalization, and a decrease in the assessment of personal accomplishment, resulting in the decline of life quality, health, and finally, in the problems of the healthcare system ${ }^{1}$. It encompasses low-work productivity, an increase in staff turnover, a decrease in the number of patients, and finally, an increase in costs. In addition, burnout also results in a negative impact on patients, because of the low quality of medical care and the rise of medical errors, leading to longer recovery periods ${ }^{1,2}$. It is worth noting that burnout syndrome has also significant negative consequences for the doctors themselves, such as disappointments in the chosen profes$\operatorname{sion}^{3}$, the conflicts in the family, alcohol abuse, the development of depression, and suicidal tendencies ${ }^{4}$.

Burnout syndrome occurs as a result of a complex interaction of social and individual factors. These include work-related stress, length of hours spent at work, high workloads, conflicts, organizational changes, and reduced social and organizational support, lack of psychological support and disturbance of family-life balance ${ }^{5}$. l'utilisation de l'épuisement émotionnel («Maslach») et des questionnaires Lazarus. De plus, des facteurs liés à la démographie, au travail et aux styles de vie ont également été évalués.

Résultats. L'évaluation du burnout émotionnel a montré un niveau élevé de burnout émotionnel dans deux groupes $(p>0,05)$. Après 6 mois depuis le début, les indicateurs d'épuisement émotionnel (EE) $(\mathrm{p}=$ $0,019)$ et de dépersonnalisation (DP) $(p=0,028)$ ont été réduits dans le groupe IG, contrairement au groupe $\mathrm{CG}$, sauf pour le manque d'accomplissement personnel (PA ) $(p=0,067)$. Cependant, après 12 mois, les indicateurs d'EE et de DP ont été diminués, en même temps l'indicateur PA était élevé dans le groupe IG $(\mathrm{p}<0,05)$. Les données de l'étude basées sur le questionnaire Lazarus (12 mois) ont montré l'efficacité de cette méthode $(\mathrm{p}<0,05)$.

Conclusions. L'utilisation de la stratégie d'adaptation d'Asimov a montré un effet positif sur l'état émotionnel des médecins de soins primaires. Une telle stratégie possède le potentiel pour la gestion de la stabilité psychologique des médecins qui ont subi un épuisement émotionnel.

Mots-clés: épuisement émotionnel, stratégie d'adaptation, médecin de premier recours.

The widespread introduction of electronic medical records and intensification of work led to a significant overload of clinicians. It results in the development of psychological stress and professional burnout ${ }^{6}$. In some countries, the rate of burnout of healthcare workers exceeds 50\%. Many studies note that the susceptibility of medical workers to burnout depends on their specialty ${ }^{7,8}$. General practitioners and specialists working in the field of primary healthcare, due to the necessity to make an initial diagnosis for undifferentiated patients, are more likely than other doctors to experience some uncertainty in the decision-making process $^{10}$ and associated stress and burnout?

Up to date, some reports and recommendations on the prevalence of burnout have been published, however the progress on the treatment and prevention of emotional burnout is still insufficient ${ }^{11-13}$. From well-known practices, the help of professional psychologists or coaching services with solving the problems of burnout is still limited for healthcare workers, particularly in low-income countries ${ }^{14}$.

The current methods for overcoming burnout are sub-divided into doctor-oriented and organization-oriented. The doctor-oriented approach includes cognitive-behavioural methods to enhance professional competence and improve communication and cognitive skills. Organization-oriented interventions 
consist of decisions aimed at reducing the workload, optimization of teamwork, and encouraging the participation of doctors in decision-making ${ }^{15}$. Such an approach demonstrated an advantage in comparison with the doctor-oriented method ${ }^{16}$.

In fact, the evaluation of methods aimed at the reduction of the occurrence of burnout among doctors showed limited use in randomized trials ${ }^{1}$. The average duration of some studies did not exceed one week, which is, definitely not, enough to method validation. Longer studies are needed to assess the medium and long-term effects of coping strategies ${ }^{17}$.

In a study conducted by Gregory et al, doctors were asked to reduce their workload in order to decrease the main symptoms of burnout ${ }^{18}$. According to the results of this study, the indicators of emotional exhaustion and depersonalization were diminished (after 3 and 6 months). However, the disadvantage of this study was the lack of randomization.

Up to date, there is not enough data about the emotional burnout of healthcare professionals in Central Asia, particularly about primary healthcare workers in Kazakhstan. One of rare studies on the emotional burnout syndrome of medical staff conducted in a cardiology hospital (Almaty, Kazakhstan) showed a rather high level of depersonalization among doctors and nurses ${ }^{19}$; however, no coping strategies were used in this study.

The AIM OF THIS STUDY was to evaluate the effectiveness of Asimov's coping strategy in reducing emotional burnout among a group of primary care physicians in Almaty, Kazakhstan. It was dictated by the high prevalence of stress among physicians, its negative consequences for the healthcare system, and the lack of data on the level of emotional burnout of primary care professionals in the Republic of Kazakhstan.

\section{Materials AND Methods}

All protocols pertaining to human subjects were first approved by the Ethical Committee of S.D. Asfendiyarov Kazakh National Medical University, Almaty, Kazakhstan (protocol LEC No 4 (81) by 27. 03. 2019). All procedures performed in studies involving human participants were in accordance with the 1964 Helsinki declaration and its later amendments or comparable ethical standards. Informed consent was obtained from all volunteers included in the study.

\section{Study participants}

The study was conducted in Almaty, Kazakhstan. Two out-patient-clinics from each of the eight city districts were randomly selected (total: 16 clinics).

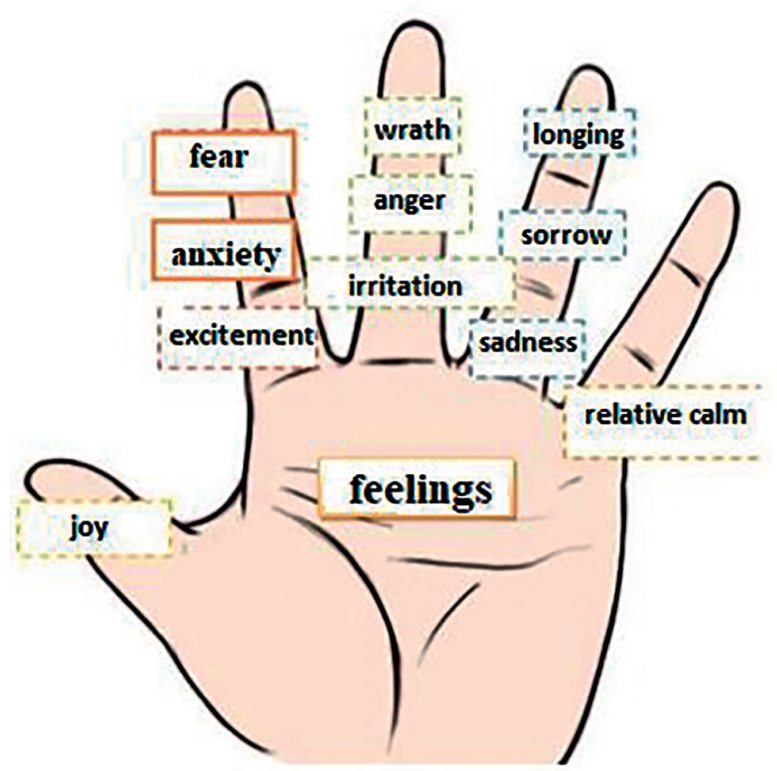

Figure 1. Scheme of recruitment of study participants.

Questionnaires were sent to all doctors (involved in primary healthcare) in selected polyclinics $(\mathrm{N}=560)$. Initially, an invitation to participate in this study, informed consent, along with the detailed information and instructions, were sent by e-mail.

In case of the consent of the participants, web-based questionnaires were sent out. Figure 1 shows that 42 participants $(7.5 \%)$ refused to participate at the initial stage, while 60 participants $(10.7 \%)$ did not provide the results of the questionnaire. Of the remaining 458 participants, 215 participants (38.3\%) were not included in the study for some reasons, such as the absence of informed consent, incompleteness or unfilling out of the questionnaire, etc.

Inclusion criteria: the participant must be a practicing physician of the primary health-care system in Almaty; he/she should have at least one year of work experience; he/she must provide signed informed consent.

Exclusion criteria: incomplete filling out of questionnaires, refusal to participate in the study, lack of informed consent, dismissal from work.

The remaining participants $(n=243)$ were assigned with an individual number, after which they were randomized using online random tools (experimental and control groups into two groups):

- group of control (CG): intervention was not done;

- intervention group (IG): the participants individually underwent short-term psychotherapy based on the coping strategy (Asimov method) at the beginning of the study, after 6 and 12 months).

The experimental $(\mathrm{n}=121)$ and control $(\mathrm{n}=$ 122) groups underwent online testing according to 
the questionnaire at the beginning of the study (after 6 and 12 months), a total of 3 measurements were obtained for each group of participants.

Thus, for a randomized trial, $243(43.3 \%)$ of the 560 participants were included. In the experimental group, $37(6.6 \%)$ participants refused to continue before the start of the study. The main reasons were: 1$)$ no time $=2(0.35 \%), 2)$ not suitable time $=3(0.53 \%)$, 3) personal reasons $=11(1.96 \%), 4)$ unidentified reasons $=20(3.57 \%)$, and 5$)$ willing to quit $=1(0.17 \%)$.

Before the procedure, $42(7.5 \%)$ study participants refused to participate in the control group (example reasons: no time $=9(1.6 \%)$, unsuitable time $=$ $3(0.53 \%)$, personal reasons $=11(1,96 \%)$, unknown reasons $=9(1.6 \%)$, and willing to quit $=3(0.53 \%)$. All stages of the study were completed by 52 (9.2\%) participants in the experimental group and by 60 (10.7\%) participants in the control group.

\section{Criteria for evaluation}

All participants were asked to fill out online forms at the beginning of the study (after 6 and 12 months). They also received a reminder (by email) about the need of filling out the questionnaires.

The questionnaire was available for filling out within one week from the date of receiving the email. Participants completed their own survey using 'SurveyMonkey' $\odot$ programme. The questionnaire consisted of several parts: demographic data, questions on determining the level of emotional burnout according to 'Maslach', and questions from the Lazarus „coping strategy" questionnaires.

1. As in many standard studies evaluating employee' burnout, demographic data were collected, which included age, gender, marital status, and the presence of children. Data on the characteristics of employment included the degree of qualification in the specialty, time of employment, the nature of work, the total time of the workload (for 1 month), and the average duration of sleep per day.

2. The use of the Maslach Emotional Burnout Questionnaire (MBI-HSS MP) in the study was dictated by the fact that this questionnaire is the most widely used tool for measuring burnout among healthcare provider ${ }^{20}$. The questionnaire consists of 22 criteria, and it evaluates three aspects of the burnout syndrome: emotional exhaustion (EE), depersonalization (DP), and lack of personal achievement (PA) according to the 6-point Likert model, where the scale is from 0 (never) to 6 (every day). Each subscale has been evaluated individually and assessed on a continuous scale ${ }^{13}$.

A high degree of burnout was recorded if the indicators were equal to $\mathrm{EE} \geq 27$ points, $\mathrm{DP} \geq 10$ and PA <33. Moderate burnout was determined in the case of $26<\mathrm{EE}<19$ points, $6<\mathrm{DP}<9$ points and $34<\mathrm{PA}<39$ points. Low levels of burnout have corresponded to $\mathrm{EE} \leq 18$ points, $\mathrm{DP} \leq 5$ points, and $\mathrm{PA}$ $\geq 40$ points $^{21}$.

The 9-point Emotional Exhaustion (EE) scale measures the feeling of emotional overwork and exhaustion at work. The 5-element Depersonalization Scale (DP) measures the insensitive and impersonal response to recipients of services, care, treatment, or education. Higher grades correspond to greater degrees of experimental burnout. The Personal Achievement Scale (PA), consisting of 8 points, measures feelings of competence and success in working with other people. A 6-point professional performance scale measures a sense of competence and success in a job. This sense of personal success emphasizes the efficiency and success in exerting beneficial effects on people. A 5-point cynicism scale measures indifference or distance relation to one's work. Cynicism, as measured by this scale, is a mechanism that allows to distance oneself from the debilitating job requirements ${ }^{21}$.

To test the reliability of the Maslach test, tau-equivalent reliability (a measurement of internal consistency; 'Alpha Cronbach') was calculated. For the samples, a coefficient of emotional burnout was chosen to be 0.90 ( 0.87 for emotional burnout, 0.80 for depersonalization, and 0.83 for lack of personal achievement).

3. In addition, coping was also assessed by using Lazarus method. The technique is designed to determine coping mechanisms, ways to overcome difficulties in various fields of mental activity, and coping strategies. The questionnaire is considered the first standard technique in the field of measuring coping. The technique was first developed by Lazarus and Folkman in 1988, and then, it was adapted by Kryukova, Kuftyak, and Zamyshlyaeva in $2004^{22}$. According to this method, a health professional is offered 50 statements regarding behaviour in difficult life situations. The test subject must evaluate how often these behavioural patterns appear in his/her life. The Lazarus „copy-strategy“ questionnaire allows identifying the following indicators: confrontive coping, distancing, self-control, seeking social support, accepting responsibility, escape-avoidance, planful problem-solving, a positive reappraisal. This technique aims at analyzing the preferred behaviours in difficult life situations. When answering each question, a point is awarded on a scale where 0 (never), 1 (rarely), 2 (sometimes), and 3 (often).

The maximum value on the question that the subject can score is 3, and for all answers is overall a maximum of 18 points. According to the results, scores from 0 to 6 refer to a low level of tension, which indicates an adaptive version of coping. Points 


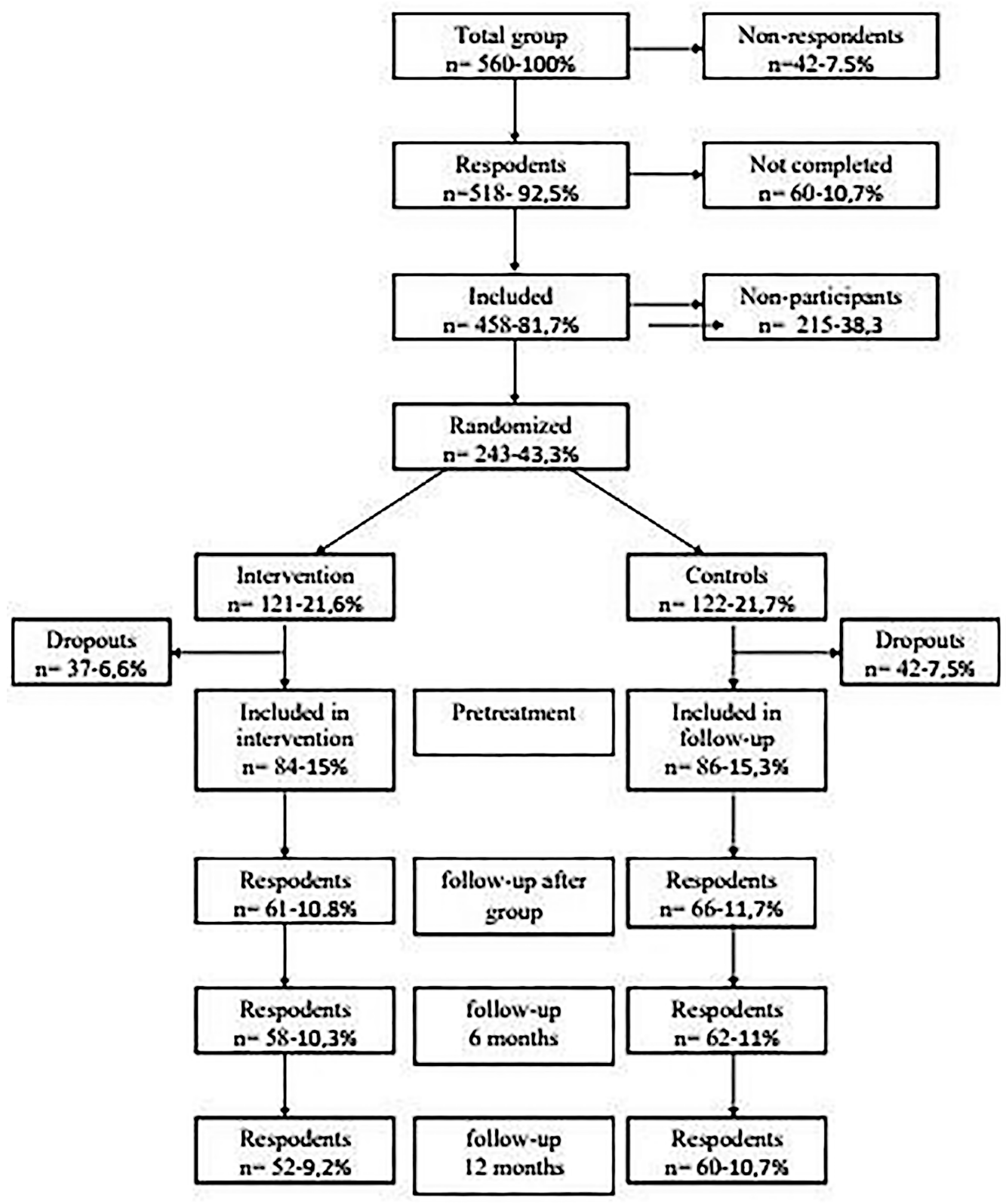

Figure 2. Determination of feelings by Asimov's method. The vital part of Asimov method is the distribution of feelings on the fingers of the palm that plays an important role for quick memorization. According to this method, there are 11 feelings: joy, excitement, anxiety, fear, sadness, sorrow, longing, irritation, anger, wrath and relative calm. It is important to note that on three fingers the feelings are marked in increasing order. Relative calm is the state when the prevailing feeling cannot be distinguished. It is desirable to find a specific feeling from the remaining 10 feelings.

from 7 to 12 correspond to the average adaptive potential of a person in a borderline state, whilst the points from 13 to 18 indicate a high coping tension, reflecting a pronounced maladaptation.

\section{Intervention}

In the experimental group, the method of short-term psychotherapy (Asimov's method) was applied based on the coping strategy, which consists of five successive steps: $-1^{\text {st }}$ step - differentiation and self-knowledge;

$-2^{\text {nd }}$ step - awareness of the state through induced images;

- $3^{\text {rd }}$ step - awareness of the state through spontaneous images with closed eyes;

- $4^{\text {th }}$ step - awareness of the state through spontaneous images with open eyes;

$-5^{\text {th }}$ step - environmentally friendly behaviour.

At the beginning of the study, psychometric research methods were carried out. After this, individual 
short-term psychotherapy based on a coping strategy was conducted (duration: 9-12 times a month for 50 minutes). Sessions of short-term psychotherapy were carried out using video communication. Short-term psychotherapy was repeated after 6 months and 12 months. All video materials of the interview were recorded, after subsequent decryption were deleted.

Participants have been taught the skill of observing and differentiating a state. The main meaning of this technique is founded on the fact that the mental state consists of feelings, sensations, and images. In this regard, the assessment of the psychological state is based on identifying three factors ('triad'): feelings, sensations, and images. The 'sensations' include heat, warmth, coolness, cold, pain, heaviness, tightness, trembling, compressing, crushing, bursting, pricking, twisting, choking, numb, numbness, dryness, humidity, tightens, and yanks. It is important to clarify the localization of sensation (in the upper/ lower body, in the extremities, irradiation of sensation). It is also necessary to examine the internal state and find sensation in every part of the body, organs, and the whole body as well. The 'feelings' encompass joy, calm, excitement, anxiety, fear, irritation, anger, wrath, sadness, sorrow and longing (Figure 2). The 'images' were defined as clear or incomprehensible. Then, through the induced images, the method acts on a subconscious level, helps the participant to realize his condition with the help of feelings, sensations.

In phases 3 and 4, the mental state is assessed and defined through spontaneous images with closed/ open eyes of the participant. The participant experiences a stressful situation with the help of spontaneous images. For self-perception of emotional state, a sequence of changing images, and the corresponding feelings and sensations are necessary as a condition for controlling the mind's state ('image-feeling-sensation' triad).

At the last step, the participant learns the skill of environmental behaviour through awareness of his/her condition It leads to the formation of an effective system of behavioural strategies in stressful situations, and the creation of adaptive mechanisms. The essence of environmental behaviour is awareness and realizing feelings, images, sensations, leading to the development of the skill of expressing one's state. Thus, through the expression of feelings and thoughts, a person could come to environmental verbalization in communication with society. In this context, manifestation and expression of feelings are different concepts. However, manifesting a negative state (for example: frowning, shouting, crying) can result in conflicting behaviour, whilst the expressing a mindful state (for example, using expressions such as „I think ...", „I feel ..." one can help to achieve an 'environmental behaviour'.

\section{Statistical analysis}

Statistical analysis was performed using SPSS 22.0 software (USA). Numerical data were presented as mean \pm standard deviation (SD). ANOVA (analysis of variance) method was used for statistical analysis. The results were calculated using confidence intervals of average values for the compared groups. The error of the mean values and the arithmetic mean did not exceed $5 \%$. In all cases, $\mathrm{P}<0.05$ was considered statistically significant. The Kolmogorov-Smirnov test confirmed that all variables were normally distributed ( $p$ > 0.05 ). The Leven test determined the uniformity of variances for each of the variable ( $p>0.05)$.

\section{Results}

The main characteristics of the studied population are presented in Table 1. The demographic analysis showed that among the participants, women made up $68.3 \%$ in the control and $71.1 \%$ in the experimental group.

To a greater extent, with an indicator of $75 \%$ in the control and intervention groups, the average age of respondents ranged from 31 to 40 years. With regard to marital status, the majority of respondents in the intervention group and in the control group (96.2\% and $91.7 \%$, respectively) were married. $96.2 \%$ in the intervention group and $88.3 \%$ in the control group had one or more children.

According to the characteristics of professional activity, $65 \%$ of doctors in the control group and 69.7\% in the group using the Asimov method had at least 7 years of work experience. Most of primary care physicians in the control group (55\%) and in the intervention group (52\%) worked with adult population.

Regarding the total working hours, $38.5 \%$ of respondents in the intervention group and $41.7 \%$ in the control group worked 48-56 hours each working week. The average duration of sleep of the most respondents in the control group (43.3\%) and in the intervention group (48.1\%) was 6-8 hours per day (Table 1).

According to the results, there was no statistically significant difference between age, gender, marital status and specialty of doctors in the two groups $(\mathrm{p}<0.05)$.

\section{Assessment of burnout by the questionnai- re Maslach}

The results of the assessment of emotional burnout according to the Maslach questionnaire at the beginning of the study in the two groups showed a high level of emotional burnout (Table 2). EE in the CG group (27.4 \pm 3.2$)$ and in the IG group $(28.1 \pm 2.8)$ indicators related to high depletion rates did not differ 
Table 1. Characteristics of participants depending on the study group

\begin{tabular}{|c|c|c|c|c|}
\hline Characteristic & Category & $\begin{array}{l}\text { Intervention } \\
\mathrm{N}=52(\%)\end{array}$ & $\begin{array}{c}\text { Controls } \\
\mathrm{N}=60(\%)\end{array}$ & Total \\
\hline \multirow{2}{*}{ Gender } & Women & $37(71.1)$ & $41(68.3)$ & $78(69.6)$ \\
\hline & Men & $15(28.8)$ & $19(31.6)$ & $24(30.3)$ \\
\hline \multirow{3}{*}{ Age } & $20-30$ & $6(11.5)$ & $7(11.7)$ & $13(11.6)$ \\
\hline & $31-40$ & $39(75)$ & $45(75)$ & $84(75)$ \\
\hline & $51-60$ & $7(13.5)$ & $8(13.3)$ & $15(13.4)$ \\
\hline \multirow{3}{*}{ Family status } & Married (married) & $50(96.2)$ & $55(91.7)$ & $105(93.7)$ \\
\hline & Divorced & $1(1.9)$ & $3(5)$ & $4(3.6)$ \\
\hline & Alone & $1(1.9)$ & $2(3.3)$ & $3(4.6)$ \\
\hline \multirow{2}{*}{ Children } & No & $2(3.8)$ & $7(11.7)$ & $9(8.03)$ \\
\hline & One or more & $50(96.2)$ & $53(88.3)$ & $103(92)$ \\
\hline \multirow{4}{*}{ Work experience } & From 1 to 3 years & $5(9.6)$ & $6(10)$ & $11(9.8)$ \\
\hline & At least 3 years & $8(15.4)$ & $10(16.7)$ & $18(16.07)$ \\
\hline & At least 7 years & $36(69.2)$ & $39(65)$ & $75(67)$ \\
\hline & 10 years or more & $3(5.8)$ & $5(8.3)$ & $8(7.1)$ \\
\hline \multirow[b]{2}{*}{ time busy (busy time) } & full time employment & $50(96.2)$ & $57(95)$ & $107(95.5)$ \\
\hline & $\begin{array}{c}\text { partial time of employ- } \\
\text { ment }\end{array}$ & $2(3.8)$ & $3(5)$ & $5(4,5)$ \\
\hline \multirow{3}{*}{$\begin{array}{c}\text { By type or nature of } \\
\text { work }\end{array}$} & adult & $27(52)$ & $33(55)$ & $60(53.5)$ \\
\hline & children's & $23(44.2)$ & $26(43.3)$ & $49(43.7)$ \\
\hline & howl & $2(3.8)$ & $1(1.7)$ & $3(2.7)$ \\
\hline \multirow{3}{*}{$\begin{array}{l}\text { Total working time for } \\
1 \text { week }\end{array}$} & $36-48$ hours & $7(13.5)$ & $5(8.3)$ & $12(10.7)$ \\
\hline & $48-56$ hours & $20(38.5)$ & $25(41.7)$ & $45(40.6)$ \\
\hline & 56 and more & $25(48)$ & $30(50)$ & $55(49.1)$ \\
\hline \multirow{4}{*}{$\begin{array}{l}\text { Average sleep time per } \\
\text { day }\end{array}$} & Less than 4 hours & $6(11.6)$ & $8(13.3)$ & $14(12.5)$ \\
\hline & $4-6$ hours & $19(36.5)$ & $23(38.3)$ & $42(37.5)$ \\
\hline & 6-8 hours & $25(48.1)$ & $26(43.3)$ & $51(45.5)$ \\
\hline & More than 8 hours & $2(3.8)$ & $3(5)$ & $5(4,5)$ \\
\hline
\end{tabular}

significantly from each other $(\mathrm{p}=0.059)$. DP indicators also showed a high level of burnout, with the results of $10.3 \pm 2.4$ and $10.8 \pm 1.9$ in the CG and IG groups, respectively, without a statistical difference $(\mathrm{p}=0.061)$. PA with low indices in the group CG $(34.9 \pm 4.5)$ and IG $(32.7 \pm 3.3)$ also did not differ from each other with significant statistical significance, that proves the uniformity of indicators of emotional burnout in both groups.

6 months after the start of the study (Table 3),

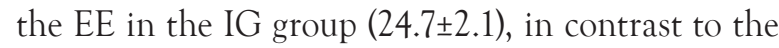
CG group (28.3 \pm 4.2$)$, demonstrated a decrease with a significant difference $(\mathrm{p}=0.019)$. On the DP scale, the IG group (8.4 \pm 1.3 ), in contrast to the CG group (10.2 \pm 2.0$)$, also showed a decrease in this indicator with a significant difference $(p=0.028)$. However, the PA indicator after 6 months in the groups CG $(33.1 \pm 1.9)$ and IG $(31.9 \pm 2.8)$ did not show significant statistical differences $(\mathrm{p}=0.067)$.
12 months after the start of the study based on the Maslach questionnaire, there was a decrease in all indicators of emotional burnout in the groups where the intervention was used, in contrast to the control group (Table 4). EE indices in the IG group with a score of $18.9 \pm 4.9$ showed a significant decrease compared to the CG group ( $\mathrm{p}=0.017)$. DP indicators in the IG group with an index of $8.4 \pm 1.3$ were reduced in contrast to CG $(11.2 \pm 0.9)$, which was considered statistically significant $(\mathrm{p}=0.01)$. PA in the $\mathrm{CG}$ group was $33.1 \pm 1.9$, however, in the IG group, this indicator increased to $42.2 \pm 3.9$, which was regarded as a positive effect of the intervention with a statistically significant difference $(\mathrm{p}=0.021)$.

\section{Evaluation of indicators for Lazarus coping method}

The results of studying coping mechanisms, including overcoming difficulties in various fields of 
Table 2. Assessment of emotional burnout of both groups (CG / IG) according to the Maslach questionnaire at the beginning of the study.

\begin{tabular}{ccccccc}
\hline \multirow{2}{*}{$\begin{array}{c}\text { Item's } \\
\text { or } \\
\text { Index }\end{array}$} & \multicolumn{2}{c}{ Emotional exhaustion (EE) } & \multicolumn{2}{c}{ Depersonalization ( DP) } & \multicolumn{2}{c}{$\begin{array}{c}\text { Absence of personal achievements } \\
\text { (PA) }\end{array}$} \\
\cline { 2 - 7 } & $\mathrm{Cg}$ & $\mathrm{IG}$ & $\mathrm{Cg}$ & $\mathrm{IG}$ & $\mathrm{Cg}$ & $\mathrm{IG}$ \\
\hline Mean & 27.4 & 28.1 & 10.3 & 10.8 & 34.9 & 32,7 \\
\hline $\begin{array}{c}\text { Standard } \\
\text { deviation }\end{array}$ & 3.2 & 2,8 & 2,4 & 1.9 & 4,5 & 3.3 \\
\hline 95\% CI & $26.1-28.9$ & $25.9-28.4$ & $8.3-11.1$ & $8.1-11.4$ & $32.8-35.2$ & $31.1-34.5$ \\
\hline Cronbach's, $\alpha$ & 0.91 & 0.90 & 0.75 & 0.78 & 0.71 & 0.76 \\
\hline $\mathrm{t}-$ Student, $\mathrm{p}$ & \multicolumn{2}{c}{$\mathrm{p}=0.059$} & $\mathrm{p}=0.061$ & $\mathrm{p}=0.079$ \\
\hline
\end{tabular}

Table 3. Assessment of emotional burnout of both groups (CG / IG) according to the Maslach questionnaire 6 months after the start of the study.

\begin{tabular}{ccccccc}
\hline \multirow{2}{*}{$\begin{array}{c}\text { Item 's } \\
\text { or } \\
\text { Index }\end{array}$} & \multicolumn{2}{c}{ Emotional exhaustion (EE) } & \multicolumn{2}{c}{ Depersonalization ( DP) } & \multicolumn{3}{c}{$\begin{array}{c}\text { Absence of personal } \\
\text { achievements ( PA) }\end{array}$} \\
\cline { 2 - 7 } & $\mathrm{Cg}$ & $\mathrm{IG}$ & $\mathrm{Cg}$ & $\mathrm{IG}$ & $\mathrm{Cg}$ & $\mathrm{IG}$ \\
\hline Mean & 28.3 & 24.7 & 10.2 & 8.4 & 33.1 & 31.9 \\
\hline Standard deviation & 4.2 & 2.1 & 2.0 & 1.3 & 1.9 & 2,8 \\
\hline 95\% CI & $26.0-28.7$ & $23.1-25.7$ & $9.2-10.9$ & $7.9-8.8$ & $30.9-34.2$ & $31.1-33.6$ \\
\hline Cronbach 's, $\alpha$ & 0.91 & 0.89 & 0,077 & 0.83 & 0.81 & 0.79 \\
\hline $\mathrm{t}$-Student, $\mathrm{p}$ & \multicolumn{2}{c}{$\mathrm{p}=0.019$} & $\mathrm{p}=0.028$ & $\mathrm{p}=0.067$ \\
\hline
\end{tabular}

Table 4. Assessment of emotional burnout of both groups (CG/ IG) according to the Maslach questionnaire, 12 months after the start of the study.

\begin{tabular}{ccccccc}
\hline \multirow{2}{*}{$\begin{array}{c}\text { Item 's } \\
\text { or } \\
\text { Index }\end{array}$} & \multicolumn{2}{c}{ Emotional exhaustion (EE) } & \multicolumn{2}{c}{ Depersonalization ( DP) } & \multicolumn{2}{c}{$\begin{array}{c}\text { Absence of personal } \\
\text { achievements ( PA) }\end{array}$} \\
\cline { 2 - 8 } & $\mathrm{Cg}$ & $\mathrm{IG}$ & $\mathrm{Cg}$ & $\mathrm{IG}$ & $\mathrm{Cg}$ & $\mathrm{IG}$ \\
\hline Mean & 29.2 & 18.9 & 11.2 & 8.4 & 33.1 & 42.2 \\
\hline Standard deviation & 1.9 & 4.9 & 0.9 & 1.3 & 1.9 & 3.9 \\
\hline $95 \%$ CI & $27.1-30.5$ & $16.9-20.8$ & $10.1-12.0$ & $7.9-8.8$ & $30.9-34.2$ & $39.0-44.1$ \\
\hline Cronbach 's, $\alpha$ & 0.88 & 0.89 & 0,081 & 0.83 & 0.81 & 0.76 \\
\hline $\mathrm{t}-$ Student criterion, $\mathrm{p}$ & \multicolumn{2}{c}{$\mathrm{p}=0.017$} & & $\mathrm{p}=0.01$ & $\mathrm{p}=0.021$ & \\
\hline
\end{tabular}

activity) based on the Lazarus copying test, showed that at the beginning of the study in the CG and IG groups for all eight indicators there was no statistically significant difference, which indicates equivalent emotional burnout in both groups (Table 5). During the period from the start of the study $(\mathrm{p}=0.83)$ and after 6 months ( $\mathrm{p}=0.49)$, there was no significant decrease in maladaptation copings in the CG group, compared with a time period of 12 months from the start with a statistically significant difference $(p=0.01)$, and in contrast to the data of IG group.

After 6 months, the IG group was characterized by indicators of "confrontive coping" $10.3 \pm 1.8$, "self-control“ $10.8 \pm 0.3$, , accepting responsibility“ $10.6 \pm 2.3$, „escape-avoidance“ $9.0 \pm 1.0$, „planful problem-solving" $9.1 \pm 0.4$ and „positive reappraisal“ $8.4 \pm 0.9$ that indicates a decrease with a significant difference in comparison with the CG group ( $p$ $<0.05)$.

In the IG group, in comparison with the start of the study, the "confrontive coping" indicator showed a decrease from $12.1 \pm 4.2$ to $5.8 \pm 0.3$ with a statistically significant difference ( $\mathrm{p}<0.05$ ) (after 12 months). The same statistically significant almost twofold decrease in "confrontive coping“ from $10.3 \pm 4.2$ to $5.8 \pm 0.3$ was observed when comparing the indicators after 6 months and 12 months ( $\mathrm{p}<0.05)$, respectively. Such indicators as „distance“, „seeking social support" and „positive reappraisal“ after 12 months, compared with the data from the questionnaire from the start 
Table 5. Evaluation of coping by Lazarus of both groups (CG / IG) at the beginning, after 6 and 12 months of the study.

\begin{tabular}{|c|c|c|c|c|c|c|}
\hline \multirow{2}{*}{ Indicators } & \multicolumn{2}{|c|}{ Study start } & \multicolumn{2}{|c|}{ In 6 months } & \multicolumn{2}{|c|}{ After 12 months } \\
\hline & $\mathrm{Cg}$ & IG & $\mathrm{Cg}$ & IG & $\mathrm{Cg}$ & IG \\
\hline Confrontive coping & $11.9 \pm 3.5$ & $12.1 \pm 4.2$ & $12.9 \pm 2.4$ & $10.3 \pm 1.8^{*}$ & $13.4 \pm 1$ & $5.8 \pm 0.3 \circ \#$ \\
\hline Distancing & $9.6 \pm 0.7$ & $10.0 \pm 1.2$ & $10.2 \pm 0.3$ & $9.4 \pm 0.2$ & $9.7 \pm 1.3$ & $8.9 \pm 1.2^{\circ}$ \\
\hline Self control & $12.9 \pm 1.7$ & $13.4 \pm 1.3$ & $11.8 \pm 3.2$ & $10.8 \pm 0.3^{*}$ & $11.8 \pm 08$ & $8.01 \pm 0.6^{\circ} \#$ \\
\hline Seeking social support & $8.7 \pm 1.6$ & $8.9 \pm 0.8$ & $8.8 \pm 0.2$ & $7.1 \pm 0.4$ & $8.7 \pm 1.5$ & $6.9 \pm 1.3^{\circ}$ \\
\hline Accepting responsibility & $12.7 \pm 1.5$ & $13.3 \pm 1.1$ & $13.1 \pm 0.7$ & $10.6 \pm 2.3$ * & $13.0 \pm 2.5$ & $8.4 \pm 1.2 \circ \#$ \\
\hline Escape - Avoidance & $13.7 \pm 0.4$ & $13.9 \pm 0.7$ & $12.9 \pm 1.1$ & $9.0 \pm 1.0 *$ & $13.8 \pm 03$ & $6.1 \pm 0.7^{\circ} \#$ \\
\hline Planful problem solving & $10.9 \pm 1.6$ & $11.9 \pm 0.7$ & $10.7 \pm 1.3$ & $9.1 \pm 0.4$ * & $10.4 \pm 1.8$ & $8.5 \pm 0.9 \circ \#$ \\
\hline Positive reappraisal & $14.2 \pm 0.3$ & $13.9 \pm 1.0$ & $14.4 \pm 0.3$ & $8.4 \pm 0.9$ * & $14.1 \pm 0.7$ & $8.1 \pm 2.4^{\circ}$ \\
\hline Student's T test & \multicolumn{2}{|c|}{$p=0.83$} & \multicolumn{2}{|c|}{$\mathrm{p}=0.49$} & \multicolumn{2}{|c|}{$\mathrm{p}=0.01$} \\
\hline
\end{tabular}

* difference of 6 months from the start of the study

- difference of 12 months from the start of the study

\# difference of 12 months from 6 months

of the study, also demonstrated a significant decrease to $8.9 \pm 1.2,6.9 \pm 1.3$ and $6.9 \pm 1.3$, respectively ( $p<$ $0.05)$. The values of "self-control" after 12 months compared with the start of the study $(13.4 \pm 1.3)$ and after 6 months with indicators of $10.8 \pm 0.3$ decreased with a statistically significant difference to $8.01 \pm 0.6$ ( $p<0.05)$. Another indicator, ,accepting responsibility" after 12 months, was significantly reduced to $8.4 \pm 1.2$, in contrast to the start of the intervention $(13.3 \pm 1.1)$ and compared with the indicator calculated after 6 months $(10.6 \pm 2.3)$.

The effect of the intervention also had a positive effect on the escape-avoidance coping indices, which was $6.1 \pm 0.7$ after 12 months. Such a decrease was statistically significant, unlike the indicators at the beginning of the study $(6.1 \pm 0.7)$ and after 6 months $(9.0 \pm 1.0)$ from the beginning of using the Asimov method ( $p$ <0.05). Data on the coping of „planful problem-solving" after 12 months also showed a significant decrease to $8.5 \pm 0.9$ compared with the start of the study in IG, when the indicators were $11.9 \pm 0.7$ $(\mathrm{p}<0.05)$. In addition, the dynamics of a significant decrease in scores on the "planful problem-solving" scale in the IG group remained the same 12 months later, in contrast to 6 months after the start of the intervention, from $9.1 \pm 0.4$ to $8.5 \pm 0.9$, respectively.

\section{Discussion}

The high prevalence and the negative impact of emotional burnout among medical workers spur the interest of researchers to find a solution to this problem ${ }^{23}$. In the presented study, the use of Asimov's coping strategy (based on the method of short-term psychotherapy) showed a consistently positive effect on the emotional burnout of primary care physicians.
It has been achieved through the step-by-step awareness of their condition and the development of adaptive mechanisms. We hypothesized that the Asimov method is able of decreasing the symptoms of emotional burnout. This hypothesis was tested by using the methodology of a randomized controlled trial with the participation of 243 primary care physicians in Almaty city (Kazakhstan).

As a strategy, the development of awareness aimed at increasing concentration in work and the ability to regulate emotions. Such an approach can be a solution for reducing stress and burnout of doctors. The development of awareness is based on flexibility, and it can be considered as the optimal strategy for clinicians, who are normally busy and overloaded with the work ${ }^{24}$. The results of the study confirmed that primary care physicians who used Asimov's coping strategy noted a decrease in burnout-induced stress (compared to the control group).

Efforts on the management of burnout-associated states are often aimed at improving resistance to a given condition, but not at identifying and eliminating the cause. However, without an understanding of the cause of burnout, the development of measures to reduce it will be unsuccessful ${ }^{18}$. In this regard, methods such as improving self-awareness and the development of self-control (based on reducing stress itself) have been recognized as effective methods to diminish negative consequences ${ }^{25}$.

Copying methods usually refer to the behavioural and psychological efforts that are used to combat stress. For example, there are studies indicating that such behavioural techniques as talking with colleagues, a break in work, the use of humour, and frequent spending time with family can significantly reduce the occurrence of emotional exhaustion 
compared to ignoring the presence of stress and keeping the stress experienced within oneself ${ }^{26}$. However, this approach requires further in-depth research and validation. It should be also noted that personal mechanisms for assessing threats and overcoming them can vary sufficiently for each person, and the occurrence of burnout will directly depend on personal qualities ${ }^{27}$. In this regard, individual work on overcoming burnout for each case would definitely be more effective. However, training programmes designed for small groups of doctors showed effectiveness in reducing stress, including depersonalization. This intervention could not be considered as a panacea for a doctor's burnout, but it is an important addition to maintaining a healthy mental state of medical professionals ${ }^{28}$.

The protection of emotional well-being of doctors is vital because the widespread occupational risks specific to the medical profession expose doctors to the risk of distress. This includes informing patients about their diseases, with a non-comforting prognosis of the diagnosis, encountering a severe reaction of patients in response, working with dying patients, making difficult clinical decisions, taking into account the risk of possible death and harm to health ${ }^{29}$.

In connection with the positive results obtained on the effectiveness of Asimov's coping strategy for the burnout of doctors, this approach can prove to be an effective method for increasing the emotional stability of doctors. Moreover, such a strategy can be applied individually and in group sessions of psychotherapy. According to the results of this study, the physicians in the control group even after a period of 12 months showed no decrease in emotional burnout that indicates the importance and relevance of psychological intervention.

There are reports on the relationship between the occurrence of burnout syndrome and factors such as gender, age, children, and the marital status of a medical worker'. However, we did not detect statistically significant differences between age, gender, marital status, and the specialty of doctors in the two groups ( $\mathrm{p}<0.05)$.

In previous studies on the assessment of emotional burnout based on the Maslach questionnaire, the stress reduction training has been focussed on the enhancement of awareness leading to a decrease in the level of depersonalization $(\mathrm{p}=0.03)^{30}$. However, in this study there was no randomization. Moreover, there was no follow-up period after the training, which cannot guarantee a sustainable effect of reducing emotional burnout. In addition, in another study, the levels of EE and the absence of PA were assessed by using the Maslach questionnaire. The results demonstrated that after 6 months the initial level of EE and PF did not show a statistically significant change towards a significant decrease in burnout $^{31}$. It indicates the need and therapeutic potential of such psychological intervention. A study on the use of 'coping-awareness' method for 8 weeks showed a change in the average EE (25.1), high DP (9.8), low PA range (38.8), low EE, average DP score and the absence of a significant difference in the PA indices ${ }^{32}$.

According to obtained results, the indicators of emotional exhaustion such as EE (18.9), DP (8.4) were significantly reduced. Moreover, it was observed a gradual raise of PA (42.2) after 12 months from the start of the study, that indicates a consistent and sustainable curing effect.

It must be noted that other studies based on the use of Lazarus coping method have been predominantly focussed on the positive reappraisal and planful problem-solving. However, the need for other coping mechanisms and alternative approaches were not ruled out ${ }^{33}$.

In our study, after 12 months of applying Asimov's coping strategy, none of the eight scales (according to the Lazarus questionnaire) showed a high coping intensity compared to the beginning of the intervention (points 13-18). Also, the average levels on the scales of "confrontive coping" and "seeking social support" gave way to low indicators, which indicates the adaptive version of coping. At the same time, high rates of severe maladaptation at the beginning of the study, such as „self-control“, „accepting responsibility" and "positive reappraisal" were transformed into an average level of tension. And on the scale of „escape-avoidance" after 12 months in the intervention group, we observed low indicators of tension, which proves the effectiveness of the method.

Given the recent challenges related to the COVID-19 pandemic, the problem of the doctors' burnout, and its prevention do not lose its relevance. Surveys showed that most of medical workers working in isolation wards of hospitals do not receive training and support for psychiatric care ${ }^{34}$. In this situation, patients and medical personnel who work at the forefront of the fight against coronavirus are the most vulnerable category to psychological stress ${ }^{35}$. However, one study came to the unexpected conclusion that, in comparison with doctors directly contacting patients with coronavirus, non-infectious doctors had a high level of emotional burnout. At the same time, physicians attending patients with COVID-19 demonstrated a high rate of personal achievement (according to questionnaires) ${ }^{36}$. These findings require further intensive research and validation.

Apart from physicians, students of medical universities, interns and residents especially, also encounter difficulties and stress-related disorders, 
particularly at the start of practical activity ${ }^{37}$. Available published data indicate that the emotional burnout of doctors begins from the start of studying at medical universities. In fact, medical students experience a high level of emotional burnout that also requires the attention and practical solution ${ }^{38}$. In this regard, the use of the Asimov coping method can be included in the curriculum of interns and residents as a preventive measure against burnout and stress-associated disorders.

\section{Conclusions}

To the best of our knowledge, this work is one of the few randomized controlled studies to evaluate the effectiveness of coping strategy on the emotional state of primary care physicians in Central Asia. Our data showed that the use of Asimov's coping strategy based on the short-term psychotherapy course had a consistently positive effect on the emotional burnout of primary care physicians. However, this study has some limitations as well. The sample size was small. It was caused by the difference in the doctors' working schedule, refusal to participate, and other reasons. In this regard, further research with larger sample size is planned in the future.

Apart from the use of such a method for doctors, this strategy can be also employed and implemented in the educational practice of medical universities in the form of short-term sessions. However, it would require intensive research and development of a program for further implementation in the process of medical training in Kazakhstan, aimed at reducing the psychological incidence and burnout among doctors.

\section{Author Contributions:}

Conceptualization, S.L. and Z.B.; methodology, M.A.; software, Sh.T. and I.F.; validation, F.B. and A.T.; formal analysis, N.U.; investigation, S.L. and Z.R.; resources, M.A. and F.B.; data curation, T.S. and K.K.; writing-original draft preparation, S.L.; writing-review and editing, Z.R, M.A., I.F.; visualization, N.U. and A.T.; supervision, S.L.; project administration, Z.R. All the authors have read and agreed with the final version of the article.

\section{Compliance with Ethics Requirements:}

„The authors declare no conflict of interest regarding this article"

„The authors declare that all the procedures and experiments of this study respect the ethical standards in the Helsinki Declaration of 1975, as revised in 2008(5), as well as the national law. Informed consent was obtained from all the patients included in the study"
„No funding for this study“

\section{Acknowledgments}

The authors would like to acknowledge Alexander S. Sagadiyev for his help in this work.

\section{References}

1. West CP, Dyrbye LN, Shanafelt TD. Physician burnout: contributors, consequences and solutions. Journal of Internal Medicine 2018;283:516-529.

2. Dewa CS, Loong D, Bonato S, Thanh NX, Jacobs P. How does burnout affect physician productivity? A systematic literature review. BMC Health Services Research 2014;14: 325.

3. Brown PA, Slater M, Lofters A. Personality and burnout among primary care physicians: an international study. Psychology Research and Behavior Management 2019;12: 169_ 177.

4. Shanafelt TD, Sloan JA, Habermann TM. The well-being of physicians. The American Journal of Medicine 2003; 114:513-519.

5. Taft TH, Keefer L, Keswani RN. Friends, alcohol, and a higher power. Journal of Clinical Gastroenterology 2011;45: e76 - e81.

6. Kroth PJ, Morioka-Douglas N, Veres S, et al. Association of electronic health record design and use factors with clinician stress and burnout. JAMA Network Open 2019; 2: e199609.

7. Shanafelt TD, Boone S, Tan L, et al. Burnout and satisfaction with work-life balance among US physicians relative to the general US population. Archives of Internal Medicine 2012;172:1377-85.

8. Tartas M, Walkiewicz M, Budziński W, Majkowicz M, Wójcikiewicz K, Zdun-Ryżewska A. The coping strategies during medical education predict style of success in medical career: a 10-year longitudinal study. BMC Medical Education 2016;16:186

9. Rothenberger D A. Physician burnout and well-being. Diseases of the Colon and Rectum 2017;60:567-576.

10. Cooke GP, Doust JA, Steele MC. A survey of resilience, burnout, and tolerance of uncertainty in Australian general practice registrars. BMC Medical Education 2013;13: 2.

11. Dissanaike S. How to prevent burnout (maybe). American Journal of Surgery 2016;212:1251-1255.

12. West CP , Hauer KE. Reducing burnout in primary care: a step toward solutions. Journal of General Internal Medicine 2015;30:1056-1057.

13. Zarei E, Ahmadi F, Sial MS, Hwang J, Thu PA, Usman SM. Prevalence of burnout among primary health care staff and its predictors: a study in Iran. International Journal of Environmental Research and Public Health 2019;16:2249.

14. Gazelle G, Liebschutz JM, Riess H. Physician burnout: coaching a way out. Journal of General Internal Medicine 2015;30:508-513.

15. Awa WL, Plaumann M, Walter U. Burnout prevention: a review of intervention programs. Patient Education and Counseling 2010;78:184-190.

16. Panagioti M, Panagopoulou E, Bower P, et al. Controlled interventions to reduce burnout in physicians. JAMA Internal Medicine 2017;177: 195. 
17. Medisauskaitea A, Kamau C. Reducing burnout and anxiety among doctors: randomized controlled trial. Psychiatry Research 2019;274:383-390.

18. Gregory ST, Menser T, Gregory BT. An organizational intervention to reduce physician burnout. Journal of Healthcare Management 2018;63:338-352.

19. Vinnikov D, Dushpanova A, Kodasbaev A, et al. Occupational burnout and lifestyle in Kazakhstan cardiologists. Archives of Public Health 2019;77: 13.

20. Matejić B, Milenović M, Kisić Tepavčević D, et al. Psychometric properties of the Serbian version of the Maslach Burnout Inventory-Human Services Survey: a validation study among anesthesiologists from Belgrade teaching hospitals. Scientific World Journal 2015; 2015:903597.

21. Maslach C, Jackson SE, Leiter MP, Schuaufeli WB. MBI manual. 3rd ed. Palo Alto, CA: Consulting Psychologists Press 1996:191-218.

22. Kryukova TL, Cuftack EV. The Questionnaire of Coping Ways (adaptation techniques WCQ ). Journal of the Practical Psychologist 2007;3: 93-112.

23. Fox S, Lydon S, Byrne D, Madden C, Connolly F, O'Connor P. A systematic review of interventions to foster physician resilience. Postgraduate Medical Journal 2018;94:162-170.

24. Ireland MJ, Clough B, Gill K, Langan F, O'Connor A, Spencer L. A randomized controlled trial of mindfulness to reduce stress and burnout among intern medical practitioners. Medical Teacher 2017;39: 409-414.

25. Zwack J, Schweitzer J. If every fifth physician is affected by burnout, what about the other four? Resilience strategies of experienced physicians. Academic Medicine 2013;88:382-389.

26. Lemaire JB, Wallace JE. Not all coping strategies are created equal: a mixed methods study exploring physicians' self reported coping strategies. BMC Health Services Research 2010;10: 208.

27. Bakker AB, Van Der Zee KI, Lewig KA, Dollard MF. The Relationship Between the Big Five Personality Factors and Burnout: A Study Among Volunteer Counselors. The Journal of Social Psychology 2006; 146: 31-50.

28. West CP, Dyrbye LN, Rabatin JT, et al. Intervention to promote physician well-being, job satisfaction, and professional ism. JAMA Internal Medicine 2013;174:527-33.
29. Shanafelt TD, Novotny P, Johnson ME, et al. The well-being and personal wellness promotion strategies of medical oncologists in the North Central Cancer Treatment Group. Oncology 2005;68:23-32.

30. Verweij H, Waumans RC, Smeijers D, et al. Mindfulness-based stress reduction for GPs: results of a controlled mixed methods pilot study in Dutch primary care. The British Journal of General Practice 2016 66:e99 - e105.

31. Selamu M, Hanlon C, Medhin G, Thornicroft G, Fekadu A. Burnout among primary healthcare workers during implementation of integrated mental healthcare in rural Ethiopia: a cohort study. Human Resources for Health 2019;17: 58.

32. Asuero AM, Queraltó JM, Pujol- Ribera E, Berenguera A, Rodriguez-Blanco T, Epstein RM. Effectiveness of a mindfulness education program in primary health care professionals: a pragmatic controlled trial. The Journal of Continuous Education in the Health Professions 2014; 34: 4-12.

33. Rodrigues AB, Chaves EC. Stressing factors and coping strategies used by oncology nurses. Revista Latino-Americana Enfermagem 2008;16:24-28.

34. Lima CKT, Carvalho PM de M, Lima I de AS, et al. The emotional impact of coronavirus 2019-Ncov (New Coronavirus Disease). Psychiatry Research 2020;287: 112915.

35. Xiang YT, Yang Y, Li W, et al. Timely mental health care for the 2019 novel coronavirus outbreak is urgently needed. Lancet Psychiatry 2020;7: 228 -229.

36. Wu Y, Wang J, Luo C, et al. A comparison of burnout frequency among oncology physicians and nurses working on the front lines and usual wards during the COVID-19 epidemic in Wuhan, China. Journal of Pain Symptom Management 2020; S0885-3924 (20) 30205-0.

37. Gunasingam N, Burns K, Edwards J, Dinh M, Walton M. Reducing stress and burnout in junior doctors: the impact of debriefing sessions. Postgraduate Medical Journal 2015:91:182-187.

38. Farrell SM, Molodynski A, Cohen D, et al. Wellbeing and burnout among medical students in Wales. International Review of Psychiatry 2019;31:613-618. 